\title{
Morphometric analysis of the foramen magnum in a sample of adult Sri Lankan skulls
}

Fernando $\mathrm{RCU}^{1}$, Ihalagedara DD ${ }^{1}$, Vadysinghe $\mathrm{A}^{2}$, Peiris $\mathrm{HRD}^{1}$, Nanayakkara $\mathrm{CD}^{1}$

${ }^{\prime}$ Department of Basic Sciences, Faculty of Dental Sciences, University of Peradeniya. ${ }^{2}$ Department of Forensic Medicine, Faculty of Medicine, University of Peradeniya. *rcumangafdo@gmail.com

The foramen magnum (FM) that transmits a large number of vital structures is an important anatomical landmark in neurosurgical procedures and forensic anthropology. The objective of the present study was to determine the dimensions and shape of the FM in a sample of adult Sri Lankan skulls. Forty-four adult skulls (32male and 12 female) were selected for the study. The sagittal (FMSD) and transverse (FMTD) diameters of the FM were measured using a sliding digital vernier caliper to the nearest $0.01 \mathrm{~mm}$ by one investigator. The area of the FM was calculated using Radinsky's formula; $\mathrm{A}=1 / 4 \times 3.14 \times \mathrm{FMTD} \times \mathrm{FMSD}$ and the index was calculated using the formula: FMTD $\times 100 / F M S D$. The skulls were visually assessed to determine the shape of the FM. The shape of the FM was recorded as round, oval, eggshaped, pentagonal, hexagonal or irregular. The mean sagittal and transverse diameter, area and index of FM in males were $34.62 \pm 2.17 \mathrm{~mm}$, $29.52 \pm 2.13 \mathrm{~mm}, 695.77 \pm 90.64 \mathrm{~mm} 2$ and $85.41 \pm 5.66$ respectively, whereas they were $33.87 \pm 2.31 \mathrm{~mm}, 28.28 \pm 1,99 \mathrm{~mm}$, $662.56 \pm 98.67 \mathrm{~mm} 2$ and $83.69 \pm 6.13$ respectively, in females. The shape of the foramen was found to be eggshaped in $34.1 \%$ and round in $27.2 \%$ of cases. The size and shape of the FM are highly variable among different world populations. Skulls in the studied sample showed smaller FM in comparison with those of African, Mediterranean and European populations. Males displayed larger mean values than females for all measured variables. 